\title{
Suggestive linkage of ADHD to chromosome 18q22 in a young genetically isolated Dutch population
}

\author{
Najaf Amin ${ }^{1}$, Yuri S Aulchenko ${ }^{1}$, Marieke C Dekker ${ }^{1,2}$, Robert F Ferdinand ${ }^{3}$, \\ Alwin van Spreeken ${ }^{4}$, Alfons H Temmink ${ }^{5}$, Frank C Verhulst ${ }^{6}$, Ben A Oostra ${ }^{1}$ and \\ Cornelia M van Duijn ${ }^{*, 1}$
}

${ }^{1}$ Genetic Epidemiology Unit, Department of Epidemiology \& Biostatistics and Clinical Genetics, Erasmus MC, Rotterdam, The Netherlands; ${ }^{2}$ Department of Neurology, University Medical Centre, Nijmegen, The Netherlands; ${ }^{3}$ De Waag Center for Forensic Psychiatry, Rotterdam, The Netherlands; ${ }^{4}$ Department of Neurology, Sint Franciscus Hospital, Roosendaal, The Netherlands; ${ }^{5}$ Department of Neurology, Amphia Hospital, Breda, The Netherlands; ${ }^{6}$ Department of Child and Adolescent Psychiatry, Erasmus MC Sophia, Rotterdam, The Netherlands

Attention deficit/hyperactivity disorder (ADHD) is a common, highly heritable, neuropsychiatric disorder among children. Linkage studies in isolated populations have proved powerful to detect variants for complex diseases, such as ADHD. We performed a genome-wide linkage scan for ADHD in nine patients from a genetically isolated population in the Netherlands, who were linked to each other within 10 generations through multiple lines of descent. The genome-wide scan was performed with a set $\mathbf{4 0 0}$ microsatellite markers with an average spacing of $\pm 10-12 \mathrm{cM}$. We performed multipoint parametric linkage analyses using both recessive and dominant models. Our genome scan pointed to several chromosomal regions that may harbour ADHD susceptibility genes. None exceeded the empirical genome-wide significance threshold, but the Log of odds (LOD) scores were $>1.5$ for regions $6 \mathrm{p} 22$ (Heterogenetic log of odds $(H L O D)=1.67$ ) and 18q21-22 (HLOD = 2.13) under a recessive model. We followed up these two regions in a larger sample of ADHD patients $(n=21,9$ initial and 12 extra patients). The LOD scores did not increase after increasing the sample size $(6 \mathrm{p} 22(\mathrm{HLOD}=1.51), 18 \mathrm{q} 21-22(H L O D=1.83))$. However, the LOD score on $6 \mathrm{p} 22$ increased to 2 when a separate analysis was performed for the inattentive type ADHD children. The linkage region on chromosome 18q overlaps with the findings of association of rs2311120 $\left(P=10^{-5}\right)$ and $r s 4149601\left(P=10^{-4}\right)$ in the genome-wide association analysis for ADHD performed by the Genetic Association Information Network consortium. Furthermore, there was an excess of regions harbouring serotonin receptors (HTR1B, HTR1E, HTR4, HTR1D, and HTR6) that showed a LOD score $>1$ in our genome-wide scan. European Journal of Human Genetics (2009) 17, 958-966; doi:10.1038/ejhg.2008.260; published online 21 January 2009

Keywords: children; homozygosity mapping; psychiatric; genome search; genetic isolate

\section{Introduction}

Attention deficit/hyperactivity disorder (ADHD) is a disruptive behaviour disorder characterized by a persistent

${ }^{*}$ Correspondence: Professor CM van Duijn, Department of Epidemiology and Biostatistics, Erasmus MC Rotterdam, Dr Molewaterplein 50, Rotterdam 3015 GE, The Netherlands.

Tel: + 311704 3394; Fax: + 311704 4657;

E-mail: c.vanduijn@erasmusmc.nl

Received 1 July 2008; revised 27 November 2008; accepted 4 December 2008; published online 21 January 2009 pattern of inattention and/or hyperactivity-impulsivity that is more frequent and severe than is typical for unaffected individuals in the same stage of development. Some impairment from these symptoms must be present in at least two settings, for example, at home and at school. ${ }^{1}$ ADHD has an onset in childhood but it can persist through adolescence and into adulthood. It has been estimated that $5-7 \%$ of children and $3 \%$ of adults are affected with ADHD. ${ }^{2,3}$ Boys are 3-4 times more often diagnosed with ADHD than girls. ${ }^{3,4}$ 
Attention deficit/hyperactivity is a complex disorder influenced by both genetic and environmental factors. Heritability estimates from twin and adoption studies show a strong genetic component ranging from 60-90\%, , $^{-10}$ and sibling relative risk estimates range from a four- to an eightfold increase. ${ }^{11,12}$

A large number of genetic studies of ADHD followed a candidate gene approach focusing mainly on the genes involved in the dopaminergic and serotonergic pathways. ${ }^{13}$ Genes studied most are the dopamine transporter gene (DAT1), which maps to 5p15, the dopamine D4 and D5 receptor genes ((DRD4, 11p15), (DRD5, 4p16)). These studies have yielded a number of replicated findings, but meta-analyses show that the associated variants are of small effect sizes, with odds ratio ranging from 1.13 to $1.9 .^{14,15}$

Until now, there have been seven independent genomewide linkage scans for ADHD. These include affected sib-pair (ASP) linkage studies ${ }^{16-24}$ and studies of extended multigenerational families. ${ }^{25,26}$ These studies suggested linkage to $1 \mathrm{p} 36,2 \mathrm{q} 21,2 \mathrm{q} 35,4 \mathrm{q} 13.2,5 \mathrm{p} 13,5 \mathrm{q} 13.1$, 5q33.3, 6q12, 6q22-23, 7p13, 7q21, 9q22, 11q22, 13q12, $14 q 12,15 q 15,16 q 23,17 p 11$, and several other regions with nominally significant evidence of linkage but no outstanding replications. The continued failure to replicate linkage findings for ADHD has led researchers to believe that genes affecting ADHD have common variants with very small effects that cannot be detected successfully with methods relying on linkage and hence advocated the use of association analysis. ${ }^{20}$ Alternatively, rare variants with strong effects may exist that fail to replicate because of family specific mutations. A recent genome-wide association study of ADHD performed by the International Multisite ADHD Genetics (IMAGE) group, which was conducted as a part of Genetic Association Information Network (GAIN), included 958 parent-child trios and 600000 single-nucleotide polymorphisms (SNPs), but failed to provide convincing evidence for a number of common risk variants. ${ }^{27}$

Although association analysis is a powerful tool to detect common variants with small effects, linkage analysis has proven successful in the detection of rare variants with large effects. Linkage, for common diseases, has been very successful in isolated populations, ${ }^{28,29}$ as drift and founder effects lead to the extinction of most rare variants, while a small number is retained, which, over subsequent generations, become frequent. ${ }^{30}$ This is crucial for linkage as it implies that genetic heterogeneity is reduced. ${ }^{31,32}$

In this study, we report the results of an independent genome-wide linkage scan of ADHD children, which was performed in a genetically isolated population in the Netherlands. We compare our linkage findings to that of the genome-wide association study of ADHD performed by the IMAGE group.

\section{Materials and methods Study population}

This study was conducted within the framework of the Genetic Research in Isolated populations (GRIP) programme. Approximately 150 individuals founded this population, located in the South West of The Netherlands, in the middle of the eighteenth century. The population expanded from 700 inhabitants in 1848 to more than 20000 inhabitants at present. For this population, a genealogical database including records for more than 100000 individuals is available.

For this study, two paediatric neurologists, to whom ADHD patients are referred in GRIP, asked all of their patients diagnosed with ADHD to participate in this study ( $n=49,22 \%$ females). ${ }^{33}$ Thirty-three (67\%) patients and their parents agreed to participate. Of these 33 patients, 2 were excluded from analysis because their genealogy could not be worked out, and 5 children were excluded because they did not fulfil the criteria used for the diagnosis of ADHD in this study. Of the remaining 26 patients, 21 were inbred, of whom only 9 patients, who could be linked to each other within no more than 10 generations, were used in the initial analysis, and all 21 inbred patients were used in the follow-up analysis.

\section{Psychiatric assessment}

The Dutch version of the National Institute of Mental Health Diagnostic Interview Schedule for Children (NIMH DISC or DISC)-IV was used to assess DSM-IV diagnoses. ${ }^{34-36 .}$ Psychologists and psychology students trained by the authors of the Dutch DISC-IV administered the DISCs. The training schedule used was similar to that used by the authors of the original English version, at Columbia University, New York. To obtain information regarding a wide range of current DSM-IV axis 1 diagnoses, parent DISCs (DISC-P) were administered during face-to-face contacts, at a community general health centre or in a children's hospital. Furthermore, lifetime ADHD symptoms were also assessed with the DISC-P. Teachers were interviewed with the ADHD section (current, not lifetime) of the teacher DISC (DISC-T) through telephone. The child version of the DISC (DISC-C) was not applied, as most of the children included in our sample were too young $(<11$ years of age). Children receiving treatment were withdrawn from medication for this study before the interview.

Phenotypic subgroups (inattentive, hyperactive/impulsive, and combined) of ADHD were formed based on application of the DSM-IV criteria that had been assessed with the DISC. Present ADHD diagnoses were based on information from both parents and teachers. Two types of ADHD diagnoses were derived: (1) 'based on one informant', and (2) 'based on two informants'. A diagnosis of ADHD based on one informant was applied when either a parent or a teacher scored six or more criteria for the 
Table 1 Baseline characteristics of the study population

\begin{tabular}{|c|c|c|}
\hline Characteristics & All & $\begin{array}{l}\text { Included in genome- } \\
\text { wide linkage analysis }\end{array}$ \\
\hline Number of patients & 26 & 9 \\
\hline $\begin{array}{l}\text { Number of inbred } \\
\text { patients }\end{array}$ & 21 & 9 \\
\hline $\begin{array}{l}\text { Number of patients who } \\
\text { received diagnosis from } \\
\text { two informants }\end{array}$ & 16 & 7 \\
\hline $\begin{array}{l}\text { Mean age at examination } \\
\text { (range) }\end{array}$ & $10(6-16)$ & $10(6-15)$ \\
\hline Females (\%) & 23.1 & 33.3 \\
\hline Mean kinship & 0.002 & 0.014 \\
\hline Mean inbreeding & 0.002 & 0.006 \\
\hline \multicolumn{3}{|l|}{ ADHD subtype } \\
\hline Inattentive & 12 & 5 \\
\hline Hyperactive-impulsive & 3 & — \\
\hline Combined & 11 & 4 \\
\hline
\end{tabular}

inattentive, hyperactive, or combined phenotype positive, whereas the other informant scored less than three criteria positive. A diagnosis of ADHD based on two informants was applied when one informant scored six or more criteria of one of the ADHD subgroups positive and the second informant scored three or more criteria positive. The threshold of 'three criteria positive' was chosen arbitrarily for the purpose of this study. The DSM-IV does not provide explicit rules for the number of criteria that need to be positive in two settings to obtain an ADHD diagnoses. It merely states that symptoms have to be present in at least two settings. If a child did not fulfil the criteria for present ADHD with the DISC-P, lifetime information from the DISC-P was used to obtain a lifetime diagnosis of ADHD. The baseline characteristics of the patients are given in Table 1.

\section{Genotyping}

Blood was drawn for all patients and their parents. DNA was extracted from peripheral leucocytes using standard procedures. ${ }^{37}$ We performed the genome-wide linkage scan on nine patients and their parents with a set of 400 fluorescently labelled, highly polymorphic microsatellite markers (distance between markers $\pm 10-12 \mathrm{cM}$ ) covering the whole genome. The remaining, distantly related, 17 patients and their parents were only typed for the markers in the regions of interest on chromosomes $6(n=12)$ and $18(n=7)$. The genotyping experiments were carried out following the manufacturer's instructions (Applied Biosystems, Foster City, CA, USA).

\section{Statistical analyses}

For the nine patients used in the initial genome-wide scan, a pedigree was extracted from the database. As the size of the pedigree was too large $(n=2206)$ to be analysed with any of the available software packages for linkage analysis, we divided the pedigree into two smaller, analysable subpedigrees using PEDCUT software. This program allows identification of sub-pedigrees that come under within a pre-specified pedigree bit-size limit that can be analysed, maximizing the size of the subgroups. ${ }^{38}$ One of subpedigrees (Figure 1a) had bit-size of 46 and contained 146 individuals (six patients) and the other subpedigree (Figure 1b) had bit-size of 19 and contained 41 individuals (three patients).

We checked all the markers for Mendelian inconsistencies using PEDCHECK, and in the case of inconsistencies, a second round of laboratory quality control was performed. In case the reasons for the problem could not be identified, the genotypes of the parents and child(ren) were set to missing. Marker allele frequencies were estimated by pooling the data from a sample of 447 people from the same population, using the maximum likelihood method as implemented in the PoolSTR software. ${ }^{39}$ Data handling and preparation of input files was done with MEGA2. ${ }^{40}$

For the genome-wide linkage analysis, we performed affected-only analyses using both dominant and the recessive models. Multipoint parametric linkage analysis under the dominant model was performed assuming a disease allele frequency of 0.001 , complete penetrance, and a phenocopy rate of 0.01 using SIMWALK2.

The recessive analysis was performed using homozygosity mapping. ${ }^{41}$ We adjusted for inbreeding using the shortest loop and a hypothetical loop capturing all cryptic inbreeding. ${ }^{42}$ The disease allele frequency was set to 0.01 . A model with complete penetrance and no phenocopies was used to perform heterogeneity log of odds (LOD) score computations with MERLIN. ${ }^{43}$ Haplotypes were constructed using SIMWALK2.

The genome-wide significance thresholds were determined empirically by performing 1000 genome-wide simulations of our data under the null hypothesis of no linkage. We used the complete pedigree, including all 2206 members, for marker simulation. Unlinked markers were dropped in the complete pedigree. Number of markers and intermarker distances were simulated according to the typed marker set. We performed linkage analysis using the subpedigrees. Disease-allele frequency, genetic models, pedigrees, and penetrances were the same as those we used in the actual linkage analysis. Genotypes of untyped individuals were set to 'missing'. For each genome screen, the highest heterogenetic log of odds (HLOD) score was recorded. The cumulative density function of the obtained 1000 maximum HLOD scores approximates the distribution of the genome-wide type I error rates. Our simulations showed that an HLOD score of 2.65 corresponds to a genome-wide type I error rate of $5 \%$ and that an HLOD of 1.78 corresponds to a genome-wide type I error of $50 \%$. 

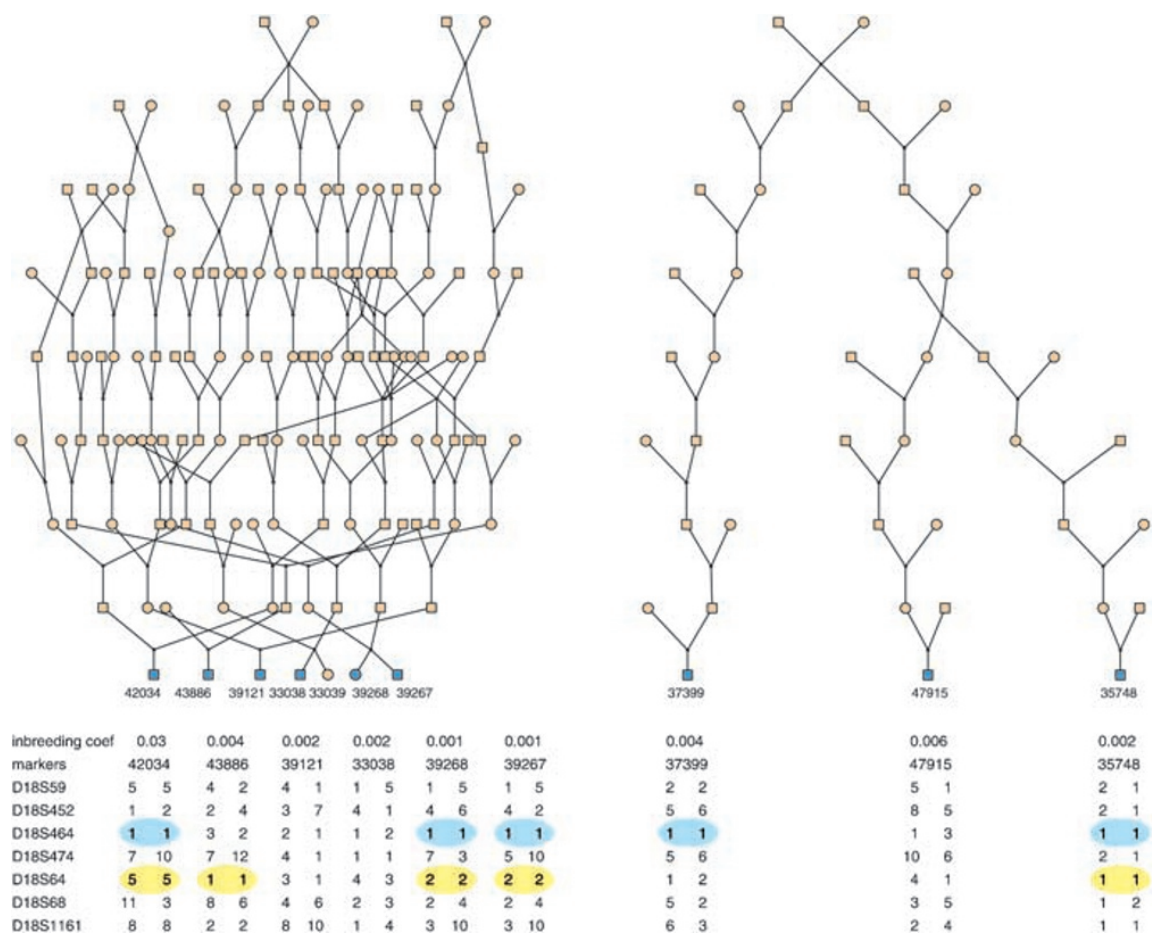

Figure 1 Subpedigrees after breaking the complete pedigree. Inbreeding coefficients and haplotypes for chromosome 18 for all nine patients are shown at the bottom.

\section{Results}

As expected, due to the selection on relationship within 10 generations, those included in the initial genome-wide linkage analysis had an almost 10-fold higher average kinship compared with that of all patients. These patients also showed an increased inbreeding coefficient, which may point to a recessive form of disease.

Results of the complete genome-wide scan from both the dominant model and recessive model with shortest and hypothetical loops are illustrated in Figure $2 \mathrm{a}-\mathrm{c}$.

There was no genome-wide significant evidence for linkage under either model. The highest LOD score under the dominant model was observed at $6 \mathrm{q} 16(\mathrm{HLOD}=0.91)$. Other regions that showed weak evidence of linkage include 2q23-24 (HLOD=0.81), 3q24 $(\mathrm{HLOD}=0.75)$, and 12 p13 $($ HLOD $=0.71)$. Homozygosity mapping yielded five genomic regions with HLOD $\geq 1$. The strongest evidence of linkage was observed at 18q21-22 (D18S64, $\mathrm{HLOD}=2.13)$. Other regions with HLOD $\geq 1$ include $6 \mathrm{p} 23$ $(\mathrm{D} 6 \mathrm{~S} 470, \mathrm{HLOD}=1.68), 6 \mathrm{p} 12 \quad(\mathrm{D} 6 \mathrm{~S} 257, \mathrm{HLOD}=1.07)$, $1 \mathrm{p} 36 \quad(\mathrm{D} 1 \mathrm{~S} 214, \quad \mathrm{HLOD}=1.09), \quad 18 \mathrm{p} 11 \quad$ (D18S59, HLOD $=1.15)$, and 15q25 (D15S205, HLOD =1.19). Details are provided in Table 2. Adjusting for multiple inbreeding loops (Figure 2c) did not alter our findings, decreasing LOD scores only marginally.

The patients' haplotypes at chromosome 18 (presented in Figure 1) show excess of homozygosity but not at a single marker. Four out of nine patients are homozygous for allele 1 of the marker D18S464. This is, however, the most common allele, with a frequency of homozygosity of 0.42. Also, at marker D18S64, five patients are homozygous: two are homozygous for allele 1, which has a frequency of homozygosity of 0.05 ; two are homozygous for allele 2, which has a frequency of homozygosity of about 0.002; and one patient is homozygous for allele 5, which has a frequency of homozygosity of $10^{-9}$.

The regions of interest on chromosomes 18 and 6 were additionally typed for the remaining distantly related 17 patients, and the data from all 21 inbred patients (Figure 3) were reanalysed. For this analysis, we used only the recessive model of inheritance as it yielded the evidence for linkage in the initial analyses.

The LOD scores did not increase by increasing the sample size, but rather decreased due to adding noninformative individuals (Figure 4). On chromosome 6p, the highest LOD score we observed was $\mathrm{HLOD}=1.51$, at marker D6S470, using homozygosity mapping. This HLOD score increased to 2 at marker D6S1574 when a recessive model with a disease allele frequency of 0.01 and complete penetrance was run separately for the 10 patients with only inattentive type ADHD (Figure 4). For chromosome 18, the highest LOD score observed was 1.83 at marker D18S1161. The haplotype analysis, however, showed that 11 out of 21 inbred patients were homozygous for the same allele at marker D18S464 (Figure 3), and 10 patients were homozygous at marker D18S64. 

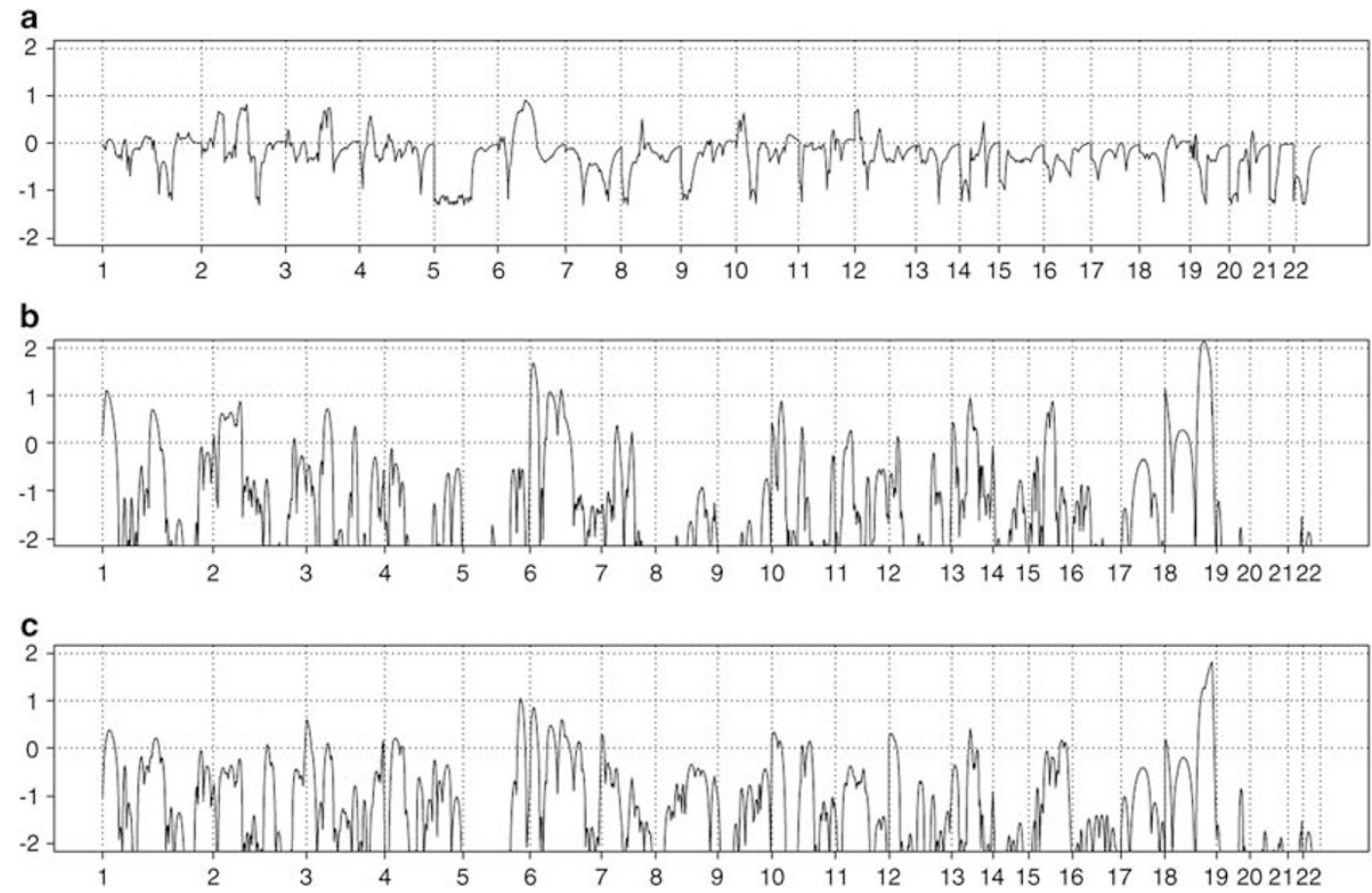

Figure 2 LOD score plots from multipoint analyses of the whole autosomal genome in nine ADHD patients. (a) Shows the LOD scores for dominant model, $\mathbf{b}$ and $\mathbf{c}$ for recessive model under homozygosity mapping with the shortest loop and hypothetical loop, respectively. The horizontal axis depicts the whole genome divided into 22 autosomes, and the vertical axis depicts the LOD scores in each panel.

Table 2 Loci with MLS $\geq 1$ under homozygosity mapping

\begin{tabular}{|c|c|c|c|c|c|}
\hline \multirow[b]{2}{*}{ Chromosome } & \multirow[b]{2}{*}{ Position (cM) } & \multirow{2}{*}{$\begin{array}{c}\text { Most likely } \\
\text { cytogenetic location }\end{array}$} & \multirow[b]{2}{*}{ Nearest marker } & \multicolumn{2}{|c|}{$\begin{array}{c}\text { Multipoint HLOD based on } \\
\text { homozygosity mapping }\end{array}$} \\
\hline & & & & Liberal $^{\mathrm{a}, \mathrm{b}}$ & Conservative $^{a, c}$ \\
\hline 1 & 17 & $1 \mathrm{p} 36$ & D1S450 & 1.1 & 0.258 \\
\hline 5 & 174 & $5 q 33$ & D5S422 & 0.73 & 1.03 \\
\hline 6 & 20 & $6 \mathrm{p} 22$ & D6S289 & 1.67 & 0.85 \\
\hline 6 & 69 & $6 \mathrm{p} 12$ & D6S257 & 1.07 & 0.47 \\
\hline 6 & 102 & $6 q 15$ & D6S462 & 1.125 & 0.58 \\
\hline 15 & 78.5 & $15 q 25$ & D15S205 & 1.19 & 0.54 \\
\hline 18 & 117 & $18 q 21$ & D18S64 & 2.13 & 1.27 \\
\hline 18 & 140 & $18 \mathrm{q} 22$ & D18S1161 & 1.2 & 1.81 \\
\hline 18 & 0 & $18 \mathrm{p} 11$ & D18S59 & 1.15 & 0.22 \\
\hline
\end{tabular}

astimated using MERLIN.

${ }^{\mathrm{b}}$ Results from the linkage analysis of pedigrees based on shortest inbreeding loop.

${ }^{c}$ Results from the linkage analysis of pedigrees constructed hypothetically using the inbreeding coefficient.

Finally, we compared our findings with those from the genome-wide association analysis of the GAIN consortium. The chromosome 18 region identified in our linkage analysis also showed evidence for association in the GAIN analysis; $r 2311120\left(P=10^{-5}\right)$, rs4149601 $\left(P=10^{-4}\right), \quad$ rs9973180 $\quad\left(P=10^{-4}\right), \quad$ and $\quad$ rs2006776 $\left(P=10^{-4}\right)$ are located in the linkage region we identified (Figure 4). These SNPs, particularly rs2311120, which was the third most significant SNP, were among the top 100 most strongly associated SNPs in the GAIN consortium. Also for chromosome $6 \mathrm{p}$ in the region we identified in our genome-wide scan, there was also some evidence of association in the GAIN study (rs2772387, $P=3 \times 10^{-4}$ ).

\section{Discussion}

We performed a genome-wide scan using two extended families from a genetically isolated Dutch population. As these pedigrees were selected based on consanguinity, we 

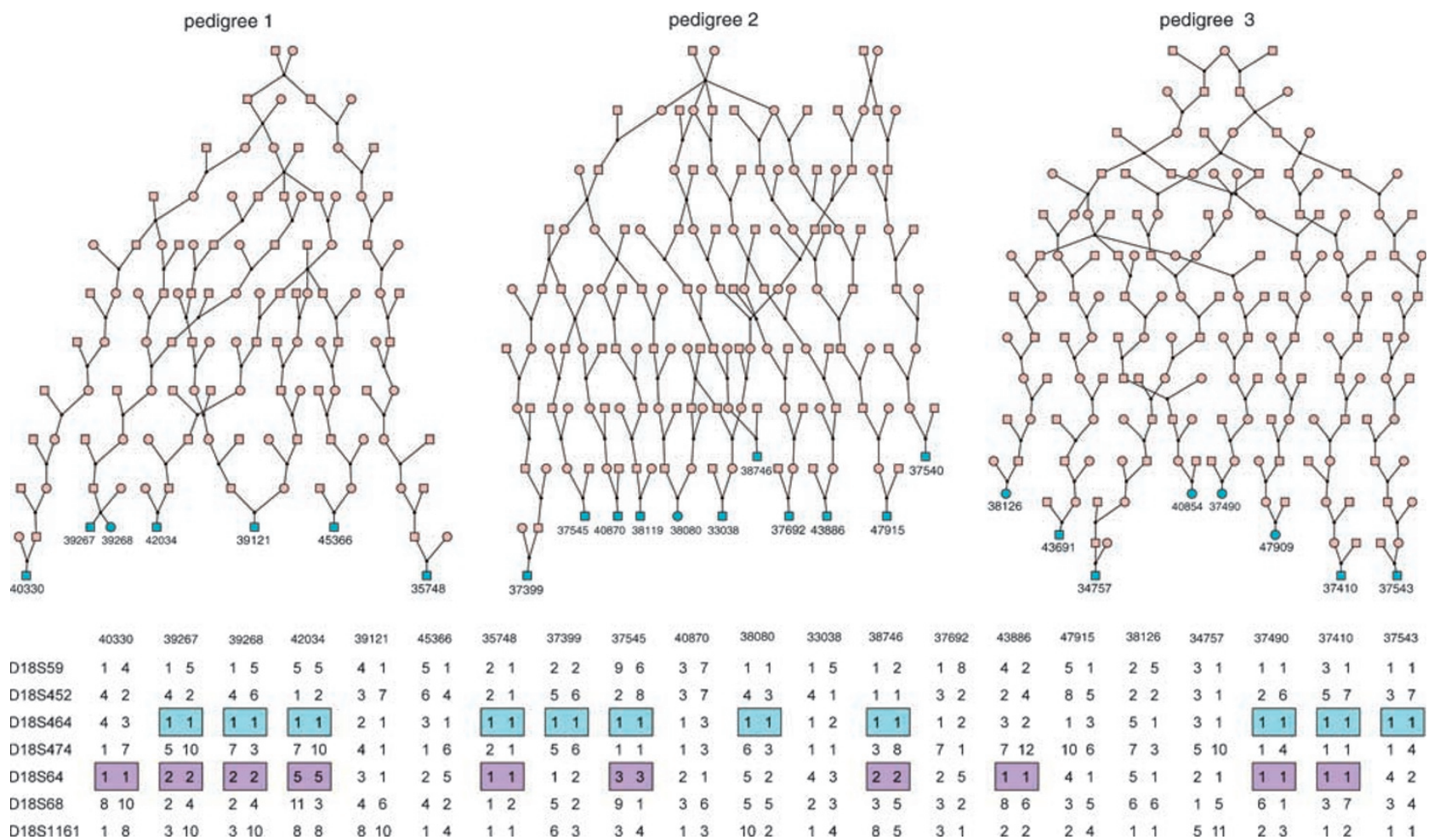

Figure 3 Subpedigrees after breaking the complete pedigree for all 26 patients and haplotypes for chromosome 18 for only the inbred patients $(n=21)$ are shown at the bottom.

selected families with recessive form of disease. There was an increased inbreeding so we did not expect a dominant form of disease. We, however, tested a dominant model because in isolated populations the disease may appear in pseudo-dominant forms. We did not observe evidence of significant or even suggestive linkage under a dominant model. Using a recessive model, we identified six genomic regions with HLOD score $>1$. Although none of these regions passed the genome-wide significance threshold, there was suggestive evidence of linkage at 18q21-22 $(\mathrm{HLOD}=2.13$, marker D18S64). The LOD score did not increase with the increase in the sample size. This may be explained by the fact that the patients selected for the genome-wide linkage analysis were the ones showing the strongest evidence for a recessive form of the disease, as the inbreeding coefficient was the highest for these patients (Table 1). The region 18q21-22 has been implicated earlier as a major susceptibility locus for bipolar disorder. ${ }^{44}$ None of the children in our sample received a clinical or DISC-P diagnosis of bipolar disorder, and none of the children received a clinical diagnosis of schizophrenia or were scored positive on the psychosis screen of the DISC-P. As none of the patients included in our study showed evidence of bipolar disorder or schizophrenia, there is no evidence of misdiagnosis explaining our finding. Considering the fact that some of the symptoms of ADHD and bipolar disorder coincide, and that ADHD in childhood increases the risk for later developing bipolar disorder, this finding suggests that this locus might harbour pleiotropic genes that increase the risk of both ADHD and bipolar disorder. Our findings are further supported by the fact that this region showed evidence of association in the GAIN study; rs2311120 was the third most significant SNP in the GAIN analysis. There were also other, less significant, SNPs in the same region (rs9973180, $P=10^{-4}$, rs2006776, $P=10^{-4}$ ) supporting the hypothesis that this region is implicated in ADHD. This region, however, did not show evidence of linkage when an ASP linkage scan ${ }^{19}$ was performed by the IMAGE group, which used a sample largely from the GAIN families.

The other interesting region in our genome-wide scan comprises of two adjacent regions on chromosome 6: 6p22-24 (HLOD 1.67, marker D6S257) and 6p12 (HLOD 1.07 , marker D6S257). $6 \mathrm{p} 22$ is one of the most frequently replicated susceptibility regions for reading disability (RD) or dyslexia, ${ }^{4-48}$ and has also been implicated as a susceptibility locus for $\mathrm{ADHD}^{49}$ in a study of ADHD within sibpairs identified for $\mathrm{RD}$. In a subanalysis of this region, the LOD score increased to $\mathrm{HLOD}=2$ (marker D6S309) when the data were analysed separately for the patients 

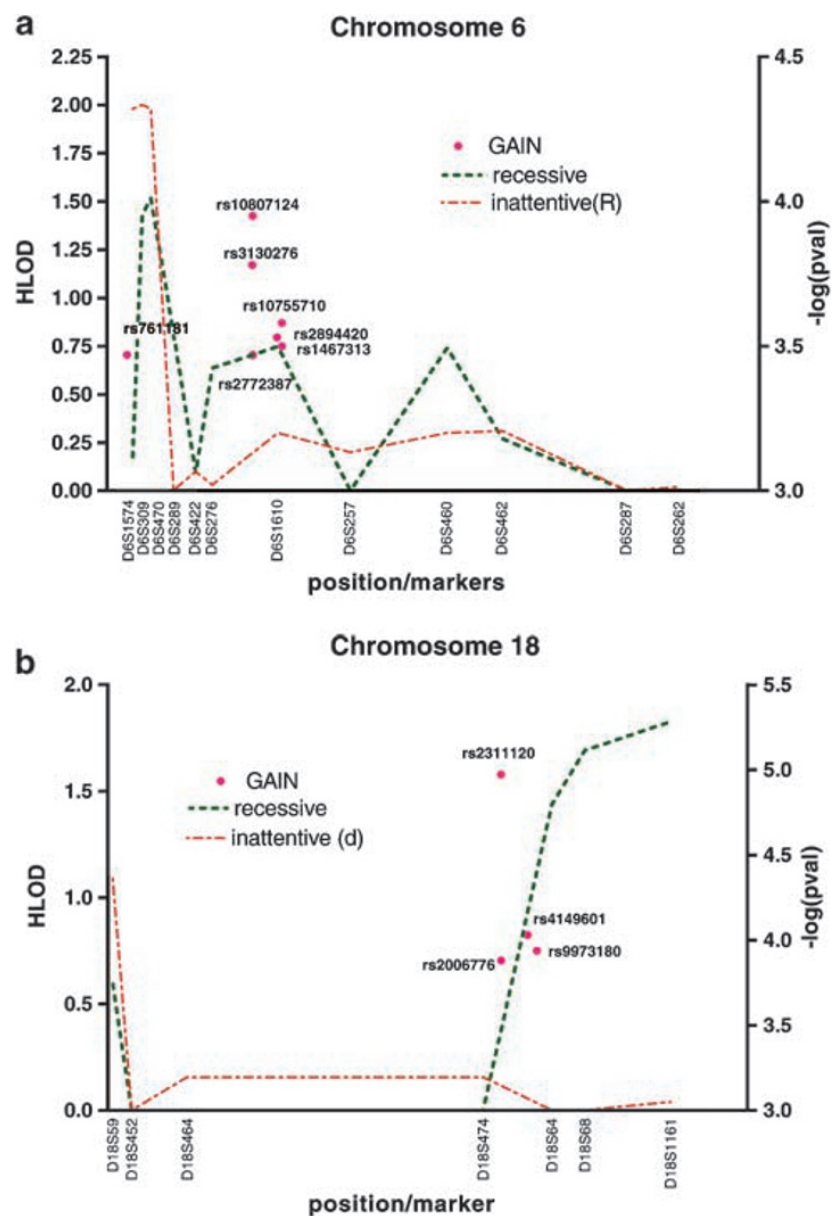

Figure 4 HLOD score plots from the follow-up multipoint analyses with increased sample size for chromosomes 6 and 18 and also the top GAIN hits for the same regions. The horizontal axis depicts the distance in base pairs, the left vertical axis depicts the LOD/HLOD scores from the linkage analysis, and the right vertical axis shows the $-\log 10$ $(P$-value) for the association analysis. The pink dots show the top hits of GAIN study in the region, the green line depicts the results from recessive model using homozygosity mapping, and the red dotted line in (a) shows the results of a recessive model run using SIMWALK2 for the inattentive subtype only and in (b) shows the results of a dominant model that was run separately for the inattentive type only using SIMWALK2.

having predominantly inattentive type ADHD. However, subgroup analyses may cause false-positive findings and remain to be confirmed. When considering other regions that were suggested by others, the region $6 \mathrm{q} 15$ that had a HLOD of 1.13 in our study and also harbours serotonin receptor genes HTR1B and HTR1E is adjacent (distance $=10 \mathrm{cM}$ ) to the region $6 \mathrm{q} 14$, which was identified by Ogdie $e t a l^{23,24}$ as a nominally significant susceptibility locus for ADHD. Our genome scan also showed some evidence of linkage to 5q33 (conservative homozygosity mapping HLOD 1.03, marker D5S422) (Figure 2c). This region harbours serotonin receptor 4 (HTR4) and was first identified with significant evidence of linkage in a genomewide scan for ADHD in an isolated population from Colombia. $^{25}$ The region 1 p36 $(\mathrm{HLOD}=1.09$, marker D1S450) has recently been identified as a susceptibility locus for ADHD with significant evidence of linkage in a linkage study of quantitative ADHD traits performed by the IMAGE group. ${ }^{22}$ This region harbours serotonin receptor 6 (HTR6) and serotonin receptor 1D (HTR1D) genes. It is of interest that each of these marginally linked regions includes serotonin receptors. HTR1B, HTR1E, HTR4, HTR1D, and HTR6 genes are known candidate genes for ADHD, although, except for HTR1B, ${ }^{50-52}$ the association of these genes with ADHD has not been established.

Although our study sample was small, the strength of our population lies in the fact that we can select patients based on genealogy. In that way, we can specifically target patients with dominant, or, in this case, recessive forms of disease based on their consanguinity. Taken together with the GAIN results, our study yields evidence that 18q21-22 may be relevant for ADHD. Our findings, in conjunction with those of GAIN, ask for further follow-up of the region. Furthermore, our study suggests that the serotonin receptors HTR1B, HTR1E, HTR4, HTR1D, and HTR6 might be implicated in ADHD.

Although isolated populations may facilitate the detection of linkage, caution is required in generalizing the results to other populations. It is, therefore, necessary that these regions be followed up in other populations. Although our findings are compatible with those of GAIN, their credibility will increase if confirmed elsewhere.

\section{Acknowledgements}

We acknowledge the collaboration of all patients, their parents, and their teachers. We thank Petra Veraart for the genealogy. We also thank Aaron Isaacs for verifying the manuscript. This study was supported by a grant from the Sophia Foundation for Scientific Research (SSWO, no. 318) and the Center of Medical Systems Biology (CMSB).

\section{References}

1 American Psychiatric Association: Diagnostic and Statistical Manual of Mental Disorders (DSM-IV), 4th edn, American Psychiatric Publishing: Washington, DC, 1994.

2 Wolraich ML, Hannah JN, Pinnock TY, Baumgaertel A, Brown J: Comparison of diagnostic criteria for attention-deficit hyperactivity disorder in a county-wide sample. J Am Acad Child Adolesc Psychiatry 1996; 35: 319-324.

3 Swanson JM, Sergeant JA, Taylor E, Sonuga-Barke EJ, Jensen PS, Cantwell DP: Attention-deficit hyperactivity disorder and hyperkinetic disorder. Lancet 1998; 351: 429-433.

4 Cantwell DP: Attention deficit disorder: a review of the past 10 years. I Am Acad Child Adolesc Psychiatry 1996; 35: 978-987.

5 Thapar A, Hervas A, McGuffin P: Childhood hyperactivity scores are highly heritable and show sibling competition effects: twin study evidence. Behav Genet 1995; 25: 537-544. 
6 Edelbrock C, Rende R, Plomin R, Thompson LA: A twin study of competence and problem behavior in childhood and early adolescence. J Child Psychol Psychiatry 1995; 36: $775-785$.

7 Faraone SV, Doyle AE: The nature and heritability of attentiondeficit/hyperactivity disorder. Child Adolesc Psychiatr Clin N Am 2001; 10: 299-316, viii-ix.

8 Gjone H, Stevenson J, Sundet JM: Genetic influence on parentreported attention-related problems in a Norwegian general population twin sample. I Am Acad Child Adolesc Psychiatry 1996; 35: 588-596; discussion 596-588.

9 Levy F, Hay DA, McStephen M, Wood C, Waldman I: Attentiondeficit hyperactivity disorder: a category or a continuum? Genetic analysis of a large-scale twin study. I Am Acad Child Adolesc Psychiatry 1997; 36: 737-744.

10 Sherman DK, Iacono WG, McGue MK: Attention-deficit hyperactivity disorder dimensions: a twin study of inattention and impulsivity-hyperactivity. I Am Acad Child Adolesc Psychiatry 1997; 36: $745-753$.

11 Smalley SL: Genetic influences in childhood-onset psychiatric disorders: autism and attention-deficit/hyperactivity disorder. Am J Hum Genet 1997; 60: 1276-1282.

12 Faraone SV, Biederman J, Monuteaux MC: Toward guidelines for pedigree selection in genetic studies of attention deficit hyperactivity disorder. Genet Epidemiol 2000; 18: 1-16.

13 Thapar A, O'Donovan M, Owen MJ: The genetics of attention deficit hyperactivity disorder. Hum Mol Genet 2005; 14 (Spec no. 2): R275-R282.

14 Faraone SV, Doyle AE, Mick E, Biederman J: Meta-analysis of the association between the 7-repeat allele of the dopamine $\mathrm{D}(4)$ receptor gene and attention deficit hyperactivity disorder. Am J Psychiatry 2001; 158: 1052-1057.

15 Maher BS, Marazita ML, Ferrell RE, Vanyukov MM: Dopamine system genes and attention deficit hyperactivity disorder: a metaanalysis. Psychiatr Genet 2002; 12: 207-215.

16 Fisher SE, Francks C, McCracken JT et al: A genomewide scan for loci involved in attention-deficit/hyperactivity disorder. Am J Hum Genet 2002; 70: 1183-1196.

17 Bakker SC, van der Meulen EM, Buitelaar JK et al: A wholegenome scan in 164 Dutch sib pairs with attention-deficit/ hyperactivity disorder: suggestive evidence for linkage on chromosomes 7p and 15q. Am J Hum Genet 2003; 72: 1251-1260.

18 Hebebrand J, Dempfle A, Saar K et al: A genome-wide scan for attention-deficit/hyperactivity disorder in 155 German sib-pairs. Mol Psychiatry 2006; 11: 196-205.

19 Asherson P, Zhou K, Anney RJ et al: A high-density SNP linkage scan with 142 combined subtype ADHD sib pairs identifies linkage regions on chromosomes 9 and 16. Mol Psychiatry 2008; 13: 514-521.

20 Faraone SV, Doyle AE, Lasky-Su J et al: Linkage analysis of attention deficit hyperactivity disorder. Am J Med Genet B Neuropsychiatr Genet 2008; 147B: 1387-1391.

21 Rommelse NN, Arias-Vasquez A, Altink ME et al: Neuropsychological endophenotype approach to genome-wide linkage analysis identifies susceptibility loci for ADHD on 2q21.1 and 13q12.11. Am J Hum Genet 2008; 83: 99-105.

22 Zhou K, Asherson P, Sham P et al: Linkage to chromosome 1p36 for attention-deficit/hyperactivity disorder traits in school and home settings. Biol Psychiatry 2008; 64: 571-576.

23 Ogdie MN, Fisher SE, Yang M et al: Attention deficit hyperactivity disorder: fine mapping supports linkage to $5 \mathrm{p} 13,6 \mathrm{q} 12,16 \mathrm{p} 13$, and 17p11. Am J Hum Genet 2004; 75: 661-668.

24 Ogdie MN, Macphie IL, Minassian SL et al: A genomewide scan for attention-deficit/hyperactivity disorder in an extended sample: suggestive linkage on 17p11. Am J Hum Genet 2003; 72: $1268-1279$.

25 Arcos-Burgos M, Castellanos FX, Pineda D et al: Attention-deficit/ hyperactivity disorder in a population isolate: linkage to loci at 4q13.2, 5q33.3, 11q22, and 17p11. Am J Hum Genet 2004; 75: $998-1014$
26 Romanos M, Freitag C, Jacob C et al: Genome-wide linkage analysis of ADHD using high-density SNP arrays: novel loci at 5q13.1 and 14q12. Mol Psychiatry 2008; 13: 522-530.

27 Neale BM, Lasky-Su J, Anney R et al: Genome-wide association scan of attention deficit hyperactivity disorder. Am J Med Genet B Neuropsychiatr Genet 2008; 147B: 1337-1344.

28 Aulchenko YS, Vaessen N, Heutink P et al: A genome-wide search for genes involved in type 2 diabetes in a recently genetically isolated population from the Netherlands. Diabetes 2003; 52: $3001-3004$

29 Vaessen N, Heutink P, Houwing-Duistermaat JJ et al: A genomewide search for linkage-disequilibrium with type 1 diabetes in a recent genetically isolated population from the Netherlands. Diabetes 2002; 51: 856-859.

30 Pardo LM, MacKay I, Oostra B, van Duijn CM, Aulchenko YS: The effect of genetic drift in a young genetically isolated population. Ann Hum Genet 2005; 69: 288-295.

31 Aulchenko YS, Heutink P, Mackay I et al: Linkage disequilibrium in young genetically isolated Dutch population. Eur J Hum Genet 2004; 12: 527-534.

32 Heutink P, Oostra BA: Gene finding in genetically isolated populations. Hum Mol Genet 2002; 11: 2507-2515.

33 Croes EA, El Galta R, Houwing-Duistermaat JJ et al: Phenotypic subtypes in attention deficit hyperactivity disorder in an isolated population. Eur J Epidemiol 2005; 20: 789-794.

34 Ferdinand RF, van der Ende J: NIMH DISC-IV: Diagnostic Interview Schedule for Children. Authorized Dutch Translation. Rotterdam, the Netherlands: Erasmus MC-Sophia, 2000.

35 Shaffer D, Fisher P, Lucas CP, Dulcan MK, Schwab-Stone ME: NIMH Diagnostic Interview Schedule for Children Version IV (NIMH DISC-IV): description, differences from previous versions, and reliability of some common diagnoses. I Am Acad Child Adolesc Psychiatry 2000; 39: 28-38.

36 de Nijs PF, Ferdinand RF, de Bruin EI, Dekker MC, van Duijn CM, Verhulst DC: Attention-deficit/hyperactivity disorder (ADHD): parents' judgment about school, teachers' judgment about home. Eur Child Adolesc Psychiatry 2004; 13: $315-320$.

37 Miller SA, Dykes DD, Polesky HF: A simple salting out procedure for extracting DNA from human nucleated cells. Nucleic Acids Res 1988; 16: 1215

38 Liu F, Kirichenko A, Axenovich TI, Duijn CMV, Aulchenko YS: An approach for cutting large and complex pedigrees for linkage analysis. Eur J Hum Genet 2008; 16: 854-860.

39 Aulchenko YS, Bertoli-Avella AM, van Duijn CM: A method for pooling alleles from different genotyping experiments. Ann Hum Genet 2005; 69: 233-238.

40 Mukhopadhyay N, Almasy L, Schroeder M, Mulvihill WP, Weeks DE: Mega2, a data-handling program for facilitating genetic linkage and association analyses. Am J Hum Genet 1999; 65: A436.

41 Lander ES, Botstein D: Homozygosity mapping: a way to map human recessive traits with the DNA of inbred children. Science 1987; 236: 1567-1570.

42 Liu F, Elefante S, van Duijn CM, Aulchenko YS: Ignoring distant genealogic loops leads to false-positives in homozygosity mapping. Ann Hum Genet 2006; 70: 965-970.

43 Abecasis GR, Cherny SS, Cookson WO, Cardon LR: Merlin - rapid analysis of dense genetic maps using sparse gene flow trees. Nat Genet 2002; 30: 97-101.

44 Freimer NB, Reus VI, Escamilla MA et al: Genetic mapping using haplotype, association and linkage methods suggests a locus for severe bipolar disorder (BPI) at 18q22-q23. Nat Genet 1996; 12: 436-441.

45 Schumacher J, Anthoni H, Dahdouh F et al: Strong genetic evidence of DCDC2 as a susceptibility gene for dyslexia. Am J Hum Genet 2006; 78: 52-62.

46 Fisher SE, Marlow AJ, Lamb J et al: A quantitative-trait locus on chromosome $6 \mathrm{p}$ influences different aspects of developmental dyslexia. Am J Hum Genet 1999; 64: 146-156. 
47 Gayan J, Smith SD, Cherny SS et al: Quantitative-trait locus for specific language and reading deficits on chromosome $6 \mathrm{p}$. Am J Hum Genet 1999; 64: 157-164.

48 Grigorenko EL, Wood FB, Meyer MS, Pauls DL: Chromosome 6p influences on different dyslexia-related cognitive processes: further confirmation. Am J Hum Genet 2000; 66: 715-723.

49 Willcutt EG, Pennington BF, Smith SD et al: Quantitative trait locus for reading disability on chromosome $6 \mathrm{p}$ is pleiotropic for attention-deficit/hyperactivity disorder. Am J Med Genet 2002; 114: $260-268$
50 Brunner D, Buhot MC, Hen R, Hofer M: Anxiety, motor activation, and maternal-infant interactions in 5HT1B knockout mice. Behav Neurosci 1999; 113: 587-601.

51 Hawi Z, Dring M, Kirley A et al: Serotonergic system and attention deficit hyperactivity disorder (ADHD): a potential susceptibility locus at the 5-HT(1B) receptor gene in 273 nuclear families from a multi-centre sample. Mol Psychiatry 2002; 7: 718-725.

52 Quist JF, Barr CL, Schachar R et al: The serotonin 5-HT1B receptor gene and attention deficit hyperactivity disorder. Mol Psychiatry 2003; 8: 98-102. 